\title{
Quantitative evaluation using single-photon emission computed tomography with acetazolamide is reliable for preoperative evaluation before cardiac surgery in severe carotid intracranial artery stenotic and/or occlusive disease: a case report
}

Eiki Tayama*, Ryusuke Mori, Tomohiro Ueda, Ken-ichi Imasaka, Yukihiro Tomita and Shigeki Morita

\begin{abstract}
Background: Severe carotid and intracranial artery stenosis disease (CIAD) is major risk for perioperative stroke in coronary artery bypass grafting. Then, preoperative risk assessment is quite important.

Case presentation: A 58-years old Japanese woman with bilateral carotid stenosis and bilateral middle cerebral artery occlusion was suffered from worsening effort angina due to severe three coronary vessel disease. Magnetic resonance imaging angiography demonstrated severe carotid and intracranial vessel stenosis. Selective carotid/ cerebral angiography also showed severe stenosis and delayed filling of the right internal carotid artery and moderate stenosis of the left internal carotid artery, with occlusion of the bilateral middle cerebral arteries. However, quantitative evaluation with brain perfusion, single-photon emission computed tomography (SPECT) with acetazolamide showed depleted cerebral perfusion volume and vascular responses, particularly in the left middle cerebral artery area. However, both sides of MCA reserve cerebral blood flow was maintained at $>34 \mathrm{ml} / 100 \mathrm{~g} / \mathrm{min}$. So, we finally considered that her cerebral perfusion reserve was maintained a certain level and could tolerate open heart surgery. Then, she underwent off-pump coronary artery grafting. Before sternotomy, prophylactic intra-aortic balloon pump support was used to minimize possible perioperative stroke. As a result, hemodynamic status and brain regional oxygen saturation were stable throughout the operation, and recovered uneventfully.

Conclusions: Preoperative quantitative evaluation using brain perfusion SPECT with acetazolamide is useful in assessing hemodynamic cerebrovascular risk in patients with severe obstructive CIAD. Off pump coronary artery bypass grafting with intra aortic balloon pump assist is a good option for prevention of cerebrovascular morbidity in ischemic heart disease with severe CIAD.
\end{abstract}

Keywords: Carotid and intracranial artery stenotic and/or occlusive disease (CIAD), Single-photon emission computed tomography (SPECT), Cerebral hemodynamics, Off-pump coronary artery bypass grafting (OPCAB)

\footnotetext{
* Correspondence: eiki@med.kurume-u.ac.jp

Department of Cardiovascular Surgery, Clinical Research Institute, National

Hospital Organization, Kyushu Medical Center, 1-8-1 Jigyohama, Chuo-ku,

Fukuoka 810-8563, Japan
}

(c) The Author(s). 2019 Open Access This article is distributed under the terms of the Creative Commons Attribution 4.0 International License (http://creativecommons.org/licenses/by/4.0/), which permits unrestricted use, distribution, and reproduction in any medium, provided you give appropriate credit to the original author(s) and the source, provide a link to the Creative Commons license, and indicate if changes were made. The Creative Commons Public Domain Dedication waiver (http://creativecommons.org/publicdomain/zero/1.0/) applies to the data made available in this article, unless otherwise stated. 


\section{Background}

Although embolism is the major cause for perioperative stroke, carotid and intracranial artery stenotic and/or occlusive disease (CIAD) is known to increase perioperative stroke and mortality risk after coronary artery bypass grafting (CABG) [1, 2]. Therefore, risk assessment and operative strategy should be carefully considered in such cases. We report a patient with bilateral carotid stenosis and bilateral middle cerebral artery occlusion who underwent coronary artery revascularization without any complications. Quantitative evaluation with brain perfusion, single-photon emission computed tomography (SPECT) with acetazolamide was useful for assessment of perfusion reserve in this patient with severe CIAD [3-5].

\section{Case presentation}

A 58-year-old Japanese woman was admitted with 6 months of recently worsening effort angina. She had no history of previous stroke, but had been treated for diabetes mellitus and hypertension for 7 years and was currently controlled, with glycosylated hemoglobin and blood pressure in normal range. Electrocardiography showed abnormal Q waves in II, III, and aVF, and downsloping ST-segment depression in V4 to V6. Echocardiography showed severe left ventricular anteroseptal hypokinesis and decreased ejection fraction of $38 \%$ without mitral regurgitation. Coronary angiography revealed total occlusion of proximal right coronary artery \#2, tandem stenosis (75 and 90\%) of the left anterior descending coronary artery, and $75 \%$ stenosis of the left circumflex coronary artery. Unfortunately, this 3-vessel coronary disease was considered inappropriate for percutaneous coronary intervention due to multiple long stenotic lesions, the patient was referred for CABG.
However, magnetic resonance imaging (MRI) angiography demonstrated severe carotid and intracranial vessel stenosis (Fig. 1). Selective carotid/cerebral angiography also showed severe stenosis and delayed filling of the right internal carotid artery (ICA) and moderate stenosis of the left ICA, with occlusion of the bilateral middle cerebral arteries (MCAs). The bilateral distal MCAs were slightly enhanced with delayed filling via collaterals from the external carotid arteries and vertebral artery (Figs. 2, 3). SPECT N-isopropyl-p-[123I]iodoamphetamine (123I-IMP) with acetazolamide showed depleted cerebral perfusion volume and vascular responses, particularly in the left MCA area. However, bilateral MCA reserve cerebral blood flow $(\mathrm{rCBF})$ was maintained at $>34 \mathrm{ml} / 100 \mathrm{~g} / \mathrm{min}$ (Fig. 4 and Table 1). Fortunately, the ascending aorta and arch were intact, without calcification or atherosclerotic debris on CT.

Despite severe CIAD, we considered that the patient could tolerate open heart surgery with appropriate perioperative circulatory management, without need for preoperative cerebral perfusion intervention. She underwent off-pump CABG (OPCAB: left internal thoracic artery to left anterior descending artery $\# 8$, right internal thoracic artery to left circumflex artery \#14, and saphenous vein graft to right coronary artery \#4). Before sternotomy, prophylactic intra-aortic balloon pump (IABP) support was used to minimize possible perioperative stroke. For proximal saphenous grafting to the ascending aorta, we used the Enclose II anastomosis assist device (Novare Surgical Systems, Inc., CA, USA). As a result, hemodynamic status and brain regional oxygen saturation were stable throughout the operation, even during displacement of the heart for posterior and inferior anastomosis (Fig. 5). The postoperative course was uneventful; weaning from both the respirator and IABP was performed on postoperative day 1 , with discharge

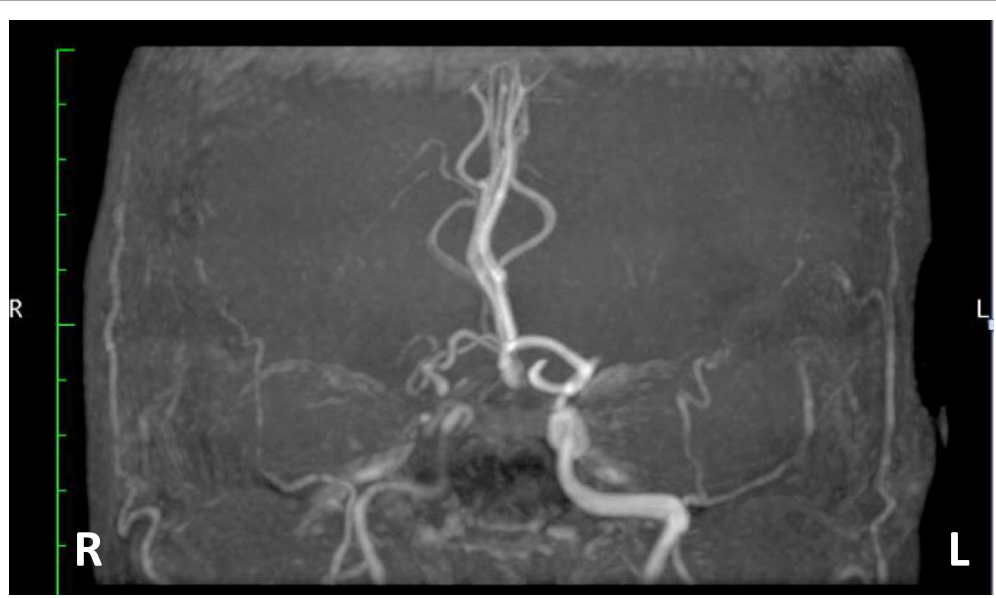

Fig. 1 Magnetic resonance imaging (MRI) angiography. MRI demonstrated stenosis in bilateral internal carotid arteries, with occluded and poorly visible bilateral middle cerebral arteries 


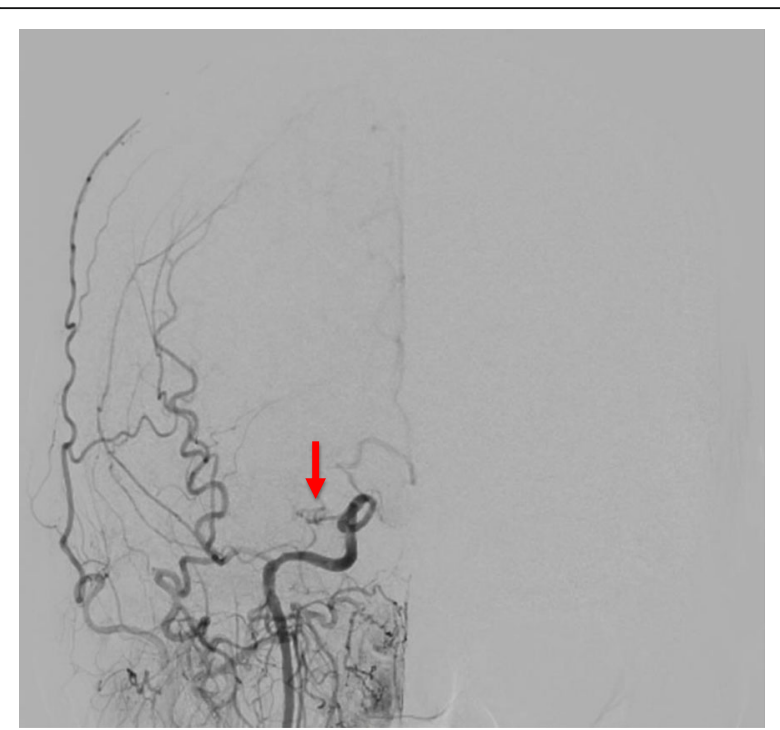

Fig. 2 Selective internal carotid artery angiography (Right). Severe stenosis with filling delay in right internal carotid artery. Right middle cerebral artery was occluded (arrow) and showed slight contrast with a filling delay through the anterior communicating artery

on postoperative day 17 without any complications. The patient has remained stable for more than 3 years.

\section{Discussion}

While CABG has played a significant role in revascularization for ischemic heart disease, neurological

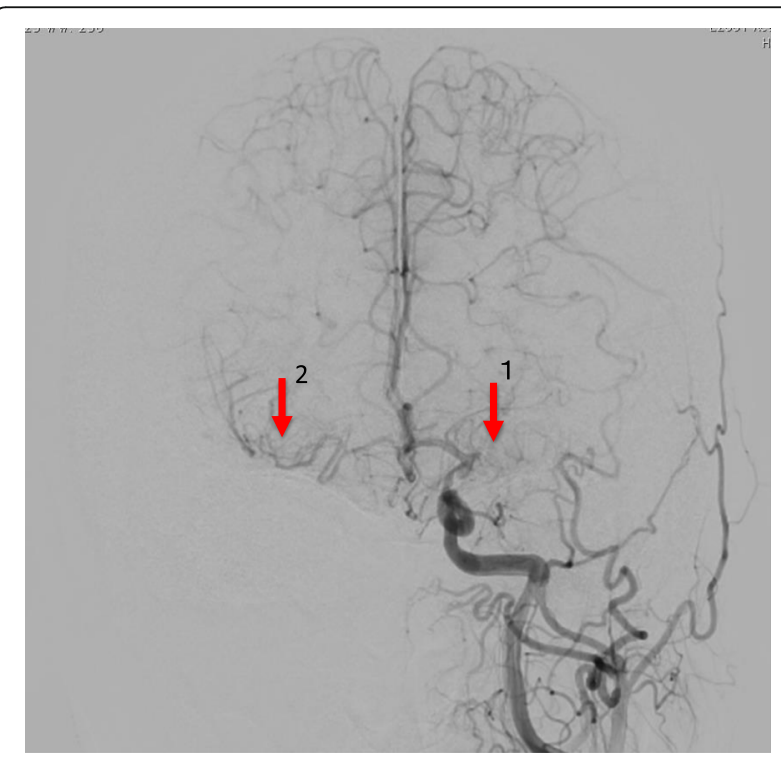

Fig. 3 Selective internal carotid artery angiography (Left). Moderate stenosis of the left internal carotid artery and total occlusion of the left middle cerebral artery (arrow 1). Slight collateral circulation (arrow 2) from the left internal carotid artery, external carotid artery, and vertebral artery to the middle cerebral artery territory complications have been a primary concern. In particular, CIAD increases perioperative stroke and mortality risk $[1,2]$.

Once CIAD is suspected on carotid ultrasound, CT, or MRI, functional evaluation is essential. As a functional test of brain circulation, SPECT is the most useful method for quantification of cerebral blood flow (CBF). Brain perfusion SPECT, particularly with use of acetazolamide, is considered capable of detecting hemodynamic compromise [3-5]. With the injection of acetazolamide, perfusion is increased in areas where the cerebral perfusion reserve is preserved, whereas areas with decreased cerebral perfusion reserve show no increase or decrease in perfusion because of the intra-cerebral steal phenomenon [3]. Reduced regional cerebral blood flow ( $<80 \%$ of normal cerebral blood flow) and reduced regional cerebral reactivity $(<10 \%$ of regional cerebral reactivity) are diagnosed as having impaired cerebral perfusion reserve (misery perfusion) [3]. In patients with misery perfusion, excessive falls in blood pressure and systemic hemodynamic disturbances lead to hemodynamic ischemic stroke [6].

An our previous report assessed obstructive CIAD in 88 patients of open heart surgery cases using brain perfusion SPECT with acetazolamide [4]. In that study, unacceptably depleted cerebral perfusion reserve was defined as $\mathrm{rCBF}$ in the ipsilateral $\mathrm{MCA} \leq 34 \mathrm{ml} / 100 \mathrm{~g} / \mathrm{min}$, with a reserve cerebral blood response of $\leq 10 \%$, based on the Japanese EC-IC bypass trial (JET study) [7]. An impaired cerebral perfusion reserve was identified in 1 (1.1\%) patients. This patient underwent prophylactic superficial temporal artery to MCA anastomosis 1 month before CABG. Subsequently, the patient underwent conventional CABG, without experiencing perioperative stroke. Seven (1.4\%) patients died in-hospital mortality and $5(1.0 \%)$ experienced embolic perioperative stroke due to paroxismal atrial fibrillation. However, no patients experienced perioperative "haemodynamic" ischaemic stroke, if cerebral reserve was acceptable range evaluated by the SPECT.

According to this definition, open heart surgery was judged to be acceptable in the present case, as long as appropriate hemodynamic status was maintained. We would like to emphasize that quantitative evaluation using brain perfusion SPECT with acetazolamide is very useful for risk assessment in CIAD patients. If cerebral perfusion reserve is judged as lower than safe limit, some preoperative prophylactic craniocervical intervention may be crucial, such as carotid artery stenting, carotid endarterectomy, and superficial temporal artery to middle cerebral artery bypass.

However, careful patient selection is essential for application of an acetazolamide challenge, because serious adverse effects can occur, such as congestive heart 


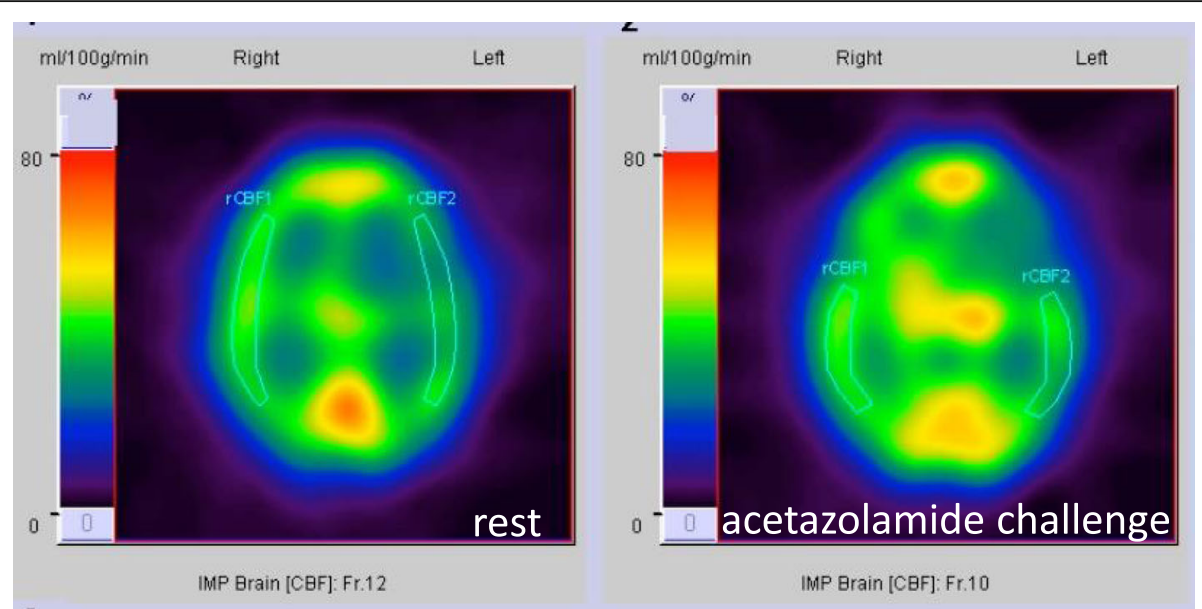

Fig. 4 Brain Perfusion SPECT (123I-IMP). Preoperative SPECT (123I-IMP) revealed significant reduction in cerebral blood flow at rest and reactivity to acetazolamide, particularly in the left MCA territory (rest and acetazolamide). SPECT: single-photon emission computed tomography. 123I-IMP: N-isopropyl-p-[123I]iodoamphetamine

failure or acute pulmonary edema. It is important to apply it only to patients who really need it. In addition, carefully monitor the clinical course, and take appropriate care promptly for possible complications are essential. On the other hand, there are no alternative test for SPECT with acetazolamide, which reproducible and having enough clinical experience.

Even if cerebral circulation reserve is adequate for open heart surgery, cerebral hypoperfusion may occur due to hypotension and declining cardiac output. This may result in diminished washout of embolic materials from blood vessels in the brain. This phenomenon is particularly likely in watershed areas along the boundaries of major arterial territories, predisposing to ischemia in these regions [8]. In addition, the risk of ischemic stroke distal to obstructive CIAD is associated with impaired cerebral autoregulation [6, 9].

Whether OPCAB or on-pump CABG is superior remains controversial. Several randomized studies comparing $\mathrm{OPCAB}$ with conventional on-pump CABG failed to show an advantage with $\mathrm{OPCAB}$ regarding stroke [10-12]. On the other hand, large retrospective studies have shown OPCAB to be associated with a lower incidence of stroke compared with that using

Table 1 Quantitative evaluation of brain perfusion using SPECT (123I-IMP) with acetazolamide

\begin{tabular}{|c|c|c|c|c|c|c|}
\hline & \multicolumn{2}{|c|}{ MCA 1} & \multicolumn{2}{|c|}{ MCA 2} & \multicolumn{2}{|c|}{ Cerebellum } \\
\hline & Rt & $\mathrm{Lt}$ & $\mathrm{Rt}$ & $\mathrm{Lt}$ & $\mathrm{Rt}$ & $\mathrm{Lt}$ \\
\hline Rest: reserve cerebral flow $(\mathrm{ml} / 100 \mathrm{~g} / \mathrm{min})$ & 34 & 36 & 33 & 35 & 38 & 39 \\
\hline Acetazolamide: rCBF (ml/100g/min) & 40 & 34 & 41 & 36 & 57 & 66 \\
\hline Vascular Response(\%) & 18 & -5 & 24 & 3 & 50 & 69 \\
\hline
\end{tabular}

SPECT single-photon emission computed tomography

123I-IMP: N-isopropyl-p-[123I]iodoamphetamine

MCA middle cerebral artery conventional on-pump CABG [13, 14]. Particularly in high risk patients, such as those with cerebrovascular atherosclerosis, severe aortic atherosclerotic, or peripheral artery disease, OPCAB reduced stroke incidence $[2,15]$. Therefore, we selected $\mathrm{OPCAB}$ for this patient. Furthermore, we applied IABP to minimize hypotension and decreased cardiac output during displacement of the heart. IABP is acknowledged to maintain cardiac function [16], and to improve CBF, particularly in patients with preexisting heart failure,

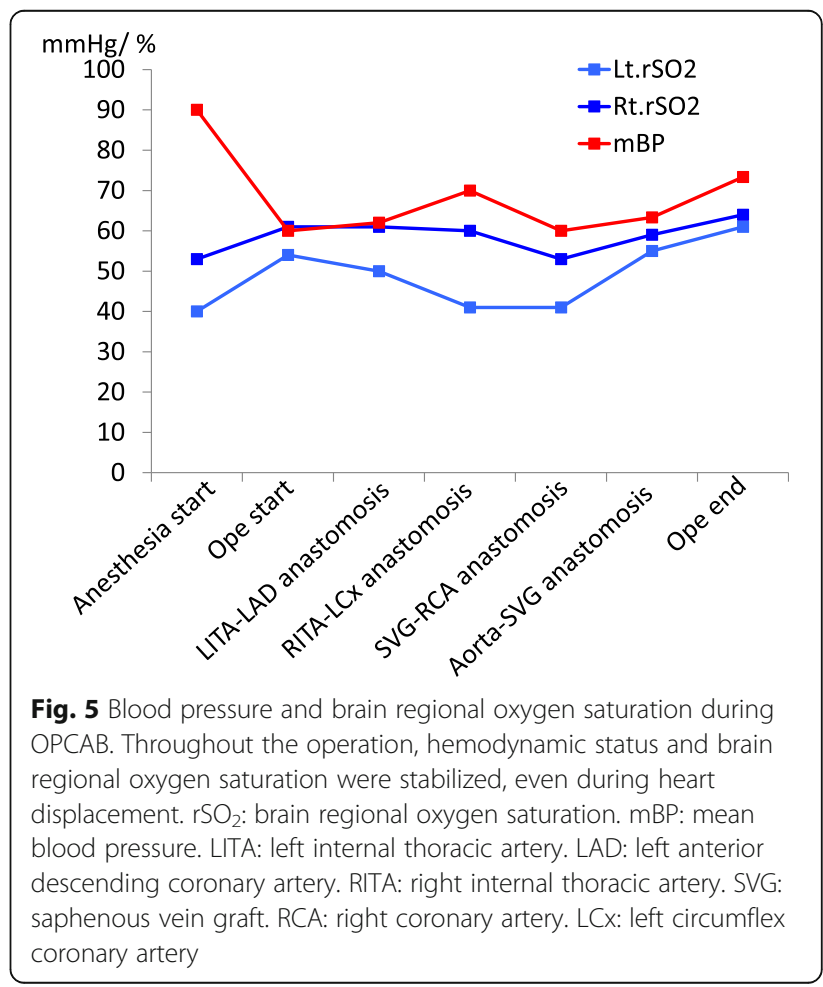


highly impaired left ventricular ejection fraction [17], and severe CIAD [18]. In animal study, augmentation of cardiac output and pulse pressure by IABC results in an increase in local CBF in ischemic brain [19].

\section{Conclusions}

Preoperative quantitative evaluation using brain perfusion SPECT with acetazolamide is useful in assessing hemodynamic cerebrovascular risk in patients with severe obstructive CIAD. OPCAB with IABP assist is a good option for prevention of cerebrovascular morbidity in ischemic heart disease with severe CIAD.

\section{Abbreviations \\ 123I-IMP: N-isopropyl-p-[123I]iodoamphetamine; CABG: Coronary artery bypass grafting; CBF: Cerebral blood flow; CIAD: Carotid and intracranial artery stenotic and/or occlusive disease; ICA: Internal carotid artery; MCA: Middle cerebral artery; MRI: Magnetic resonance imaging; OPCAB: Off- pump coronary artery bypass grafting; rCBF: Reserve cerebral blood flow; rCBR: Reserve cerebral blood response; SPECT: Single-photon emission computed tomography}

\section{Acknowledgements}

We thank Editage (www.editage.jp) for English language editing.

\section{Authors' contributions}

All authors were involved in perioperative management and surgery. ET wrote the draft of the manuscript. RM and UT obtained the data and written consent. $\mathrm{KI}$ and $\mathrm{YT}$ performed the literature review and participated in writing of the paper. All authors have read and approved the final manuscript.

\section{Funding}

This study was no funding supported.

\section{Availability of data and materials}

The data is available from corresponding author on reasonable request.

\section{Ethics approval and consent to participate}

The Kyushu Medical Center Institute Ethics Committee approved this case report for publication.

\section{Consent for publication}

Written informed consent was obtained from the patient for publication. A copy of the written consent is available for review by the Editor-in-Chief of this journal.

\section{Competing interests}

The authors declare that they have no competing interests.

Received: 24 May 2019 Accepted: 15 July 2019

Published online: 23 July 2019

\section{References}

1. Naylor AR, Mehta Z, Rothwell PM, Bell PRF. Carotid artery disease and stroke during coronary artery bypass: a critical review of the literature. Eur J Vasc Endovasc Surg. 2002;23:283-94.

2. Tsuda K, Shiiya N, Washiyama N, Yamashita K, Ohkuma K, Takahashi D, Kando Y, Natsume K, Yamanaka K, Takeuchi Y. Carotid stenosis with impaired brain flow reserve is associated with an increased risk of stroke in on-pump cardiovascular surgery. Interact Cardiovasc Thorac Surg. 2018;27:75-80

3. Kuroda S, Houkin K, Kamiyama H, Mitsumori K, Iwasaki Y, Abe H. Long-term prognosis of medically treated patients with internal carotid or middle cerebral artery occlusion: can acetazolamide test predict it? Stroke. 2001;32: 2110-6.

4. Imasaka K, Yasaka M, Tayama E, Tomita Y. Obstructive carotid and/or intracranial artery disease rarely affects the incidence of haemodynamic ischemic stroke during cardiac surgery: a study on brain perfusion singlephoton emission computed tomography with acetazolamide. Eur Cardiothorac Surg. 2015;48:739-46. https://doi.org/10.1093/ejcts/ezu502.

5. Imasaka K, Tayama E, Morita S, Tomita Y. Neurological outcome and efficacy of intensive craniocervical screening for elective cardiac surgery. Interact Cardiovasc Thorac Surg. 2018;26:216-23.

6. Yamauchi H, Fukuyama H, Nagahama Y, Nabatame H, Nakamura K, Yamamoto $Y$, et al. Evidence of misery perfusion and risk for recurrent stroke in major cerebral arterial occlusive disease from PET. J Neurol Neurosurg Psychiatry. 1996;61:18-25.

7. Mizumura S, Nakagawara J, Takahashi M, Kumita S, Cho K, Nakajo H, Toba M, Kumazaki T. Three-dimensional display in staging hemodynamic brain ischemia for JET study: objective evaluation using SEE analysis and 3D-SSP display. Ann Nucl Med. 2004;18:13-21.

8. Caplan $L R$, Hennerici M. Impaired clearance of emboli (washout) is an important link between hypoperfusion, embolism, and ischemic stroke. Arch Neurol. 1998:55:1475-82

9. Silvestrini M, Vernieri F, Pasqualetti P, Matteis M, Passarelli F, Troisi E, Caltagirone C. Impaired cerebral vasoreactivity and risk of stroke in patients with asymp- tomatic carotid artery stenosis. JAMA. 2000;283:2122-7.

10. Lamy A, Devereaux PJ, Prabhakaran D, Taggart DP, Hu S, Paolasso E, Straka Z, Piegas LS, Akar AR, Jain AR, Noiseux N, Padmanabhan C, Bahamondes JC, Novick RJ, Vaijyanath P, Reddy SK, Tao L, Olavegogeascoechea PA, Airan B, Sulling TA, Whitlock RP, Ou Y, Pogue J, Chrolavicius S, Yusuf S. Effects of off-pump and on-pump coronary-artery bypass grafting at 1 year. N Engl J Med. 2013;368:1179-88.

11. Diegeler A, Börgermann J, Kappert U, Breuer M, Böning A, Ursulescu A, Rastan A, Holzhey D, Treede H, Rieß FC, Veeckmann P, Asfoor A, Reents W, Zacher M, Hilker M, GOPCABE Study Group. Off-pump versus on-pump coronary-artery bypass grafting in elderly patients. N Engl J Med. 2013;368:1189-98.

12. Shroyer AL, Grover FL, Hattler B, Collins JF, McDonald GO, Kozora E, Lucke $J C$, Baltz JH, Novitzky D. On-pump versus off-pump coronary-artery bypass surgery. N Engl J Med. 2009;361:1827-37.

13. Nishiyama K, Horiguchi M, Shizuta S, Doi T, Ehara N, Tanuguchi R, Haruna Y, Nakagawa Y, Furukawa Y, Fukushima M, Kita T, Kimura T. Temporal pattern of strokes after on-pump and off- pump coronary artery bypass graft surgery. Ann Thorac Surg. 2009;87:1839-45.

14. Puskas JD, Kilgo PD, Lattouf OM, Thourani VH, Cooper WA, Vassiliades TA, Chen EP, Vega JD, Guyton RA. Off-pump coronary bypass provides reduced mortality and morbidity and equivalent 10-year survival. Ann Thorac Surg. 2008:86:1139-46.

15. Doi K, Yaku H. Importance of cerebral artery risk evaluation before off-pump coronary artery bypass grafting to avoid perioperative stroke. Eur J Cardiothorac Surg. 2010;38:568-72.

16. Kim KB, Lim C, Ahn H, Yang JK. Intraaortic balloon pump therapy facilitates posterior vessel off-pump coronary artery bypass grafting in high-risk patients. Ann Thorac Surg. 2001:71:1964-8.

17. Pfluecke C, Christoph M, Kolschmann S, Tarnowski D, Forkmann M, Jellinghaus S, Poitz DM, Wunderlich PC, Strasser RH, Schoen S, Ibrahim K. Intra-aortic balloon pump (IABP) counterpulsation improves cerebral perfusion in patients with decreased left ventricular function. Perfusion. 2014;29:511-6.

18. Tsukube T, Okada M, Ataka K, Ozaki N. Coronary artery bypass grafting in a patient with brain ischemia. J Cardiovasc Surg. 2001:42:349-51.

19. Tranmer BI, Peniston C, lacobacci R, Salerno TA, Hudson AR. Intra-aortic balloon counterpulsation: a treatment for Ischaemic stroke? Neurol Res. 1989;11(2):109-13

\section{Publisher's Note}

Springer Nature remains neutral with regard to jurisdictional claims in published maps and institutional affiliations. 